\title{
ENTORNO CULTURAL Y SIGNIFICACIÓN DE UN TÍTULO: OCNOS
}

\author{
Luis MARISTANY
}

El lector de Ocnos de Cernuda se halla sin duda ante uno de esos libros de título afortunado y enigmático. Curiosamente, la crítica que se ha ocupado del libro no ha abordado la cuestión, tanto en lo relativo a su entronque cultural como a su sentido dentro de la obra. Tal vez ese silencio se deba al incierto asidero que ofrece un título tan libre y a la vez tan engañosamente preciso como el de Ocnos. Cernuda declaró explícitamente su fuente - unas líneas extraídas de un ensayo de Goethe-, pero, según veremos, la trayectoria para llegar a ellas encierra su misterio y ello no agota, ni mucho menos, las resonancias de un mito tan diversamente interpretado; y por otra parte, nuestro autor decidió velar en su libro los términos de la relación entre el personaje mítico, que relegó simplemente al pórtico, y el contenido expreso de sus páginas.

No tenemos constancia, en carta ó en otro escrito de principios de los años cuarenta —es decir, cuando se gestó el libro-, ni del momento ni de las circunstancias en que tuvo lugar el hallazgo de la cita de Goethe. Las preguntas inevitables surgen: ¿fue una trouvaille, regalo de una casualidad, ese hallazgo?, ¿ocurrió en un momento avanzado de la redacción de la obra?, ¿actuó el título hasta cierto punto desgajado de los poemas, y aún del conjunto del libro, y le sirvió más bien como un oportuno marco que moderara un "cuadro" muy personal y contribuyera a potenciarlo míticamente? "Tengo el proyecto de imprimir un libro", escribió con suma parquedad, sin confesar ninguna de sus estrategias, en una carta a su amiga Nieves Mathews el 16 de abril de 1942; "este libro, casi poético, aunque no en verso, se llama Ocnos y lleva al frente unas líneas de Goethe que subrayan el significado del título". En realidad, la única referencia algo orientativa, al menos de sus intenciones, es retrospectiva y se halla en la página que escribió pocos meses antes de morir para las guardas de la tercera 
edición de Ocnos: "El librito creció, aunque no mucho, y la búsqueda de un título ocupó al autor, hasta hallar en Goethe mención de Ocnos, personaje mítico que trenza los juncos que han de servir como alimento a su asno. Halló cierta ironía justa en dar el nombre de Ocnos como título del libro, se tome al asno como símbolo del tiempo que todo lo consume, o del público igualmente inconsciente y destructor"1.

Dejemos para más adelante, una vez hayamos repasado el contexto cultural que sitúa la mención de Ocnos, el comentario de la doble interpretación sugerida al final del pasaje transcrito. Entremos poco a poco en la cuestión, en el fondo siempre enredada, de las fuentes. Y como punto de partida puede servir la frase "hasta hallar en Goethe mención de Ocnos", declaración sencilla pero que intriga y que bien merece alguna revisión. En efecto, la cita de Goethe figura en un escrito muy ocasional, Polygnots Gemälde in der Lesche zu Delphi, perdido en la ingente obra del alemán y excluido de las ediciones más comunes en lengua germana de su "opera omnia"2. Se trata, pues, de un texto sumamente raro, no sólo excluido de las ediciones corrientes sino también silenciado en el común de los libros y trabajos generales sobre Goethe. Y ni siquiera lo he visto citado en importantes estudios de tratadistas sobre Ocnos o sobre el capítulo de Pausanias acerca de las perdidas pinturas de Polignoto en Delfos. Bies es verdad que Cernuda pudo verlo mencionado por el propio Goethe en cartas a Schiller (véanse las entradas correspondientes al 27-XI, 2-XII y 13-XII-1803), un epistolario que aquél leyó con provecho y atención en Glasgow hacia 1940. Pero en esas cartas las referencias al proyecto del artículo goetheano son muy fugaces y genéricas y no encierran ninguna mención a Ocnos. En realidad, dentro de un artículo que ocupa casi cuarenta páginas de la edición consultada, al mítico soguero dedica sólo Goethe unos cuantos párrafos. Por todo ello parece muy improbable que hallara Cernuda directamente en Goethe la cita inicial de Ocnos. Debió de existir algún escrito o algún germanista mediadores; y en ese caso, una de dos: o utilizó sin más, descontextualizadamente, tal como le habría llegado, la cita de Goethe, sin ni siquiera tratar de acudir al ensayo de éste, o por el contrario, llegó a esa cita, y al ensayo, no sin cierto esfuerzo y dificultad aunque ello no excluya un arranque de azar, a la vez que procuraba documentarse antes o después más ampliamente sobre el asunto. Tratándose de un escritor instintivamente crítico como Cernuda, que además tenía a su disposición en Gran Bretaña un sistema tan bien surtido de bibliotecas, parece más sensato inclinarsse por la segunda

1. Pasajes reproducidos en: R. Martínez Nadal, Españoles en Gran Bretaña. Luis Cernuda. Madrid, Hiperión, 1983, p. 111; y Luis Cernuda, Prosa completa, Barcelona, Barral Editores, 1975, p. 1464.

2. El ensayo de Goethe "Polygnots Gemälde in der Lesche zu Delphi" únicamente se encuentra recopilado en la Sophien Ausgaben, la edición exhaustiva de su obra. He consultado Goethes Werke, herausgegeben im Auftrage deer Grossherzogin Sophie von Sachsen, Weimarer Ausgabe, 1987, I, T. 48, pp. 81-122. 
posibilidad. Parto de un supuesto: un buen poeta obra en buena parte intuitivamente y tiene la facultad de "apropiarse" un tema, es cierto; pero en diálogo con la tradición, con un conocimiento suficiente de ella. Tal fue, en todo caso, lo que habitualmente hizo Cernuda.

No es fácil, al menos para mí a pesar de las pesquisas realizadas, concretar qué itinerario le condujo al hallazgo del pasaje goetheano, o a través de qué conducto llegó a él. En las páginas siguientes, primero intentaré aproximarme a la figura de Ocnos según la tradición, pero lo haré de una forma quebrada aprovechando ciertos indicios que me permitan de paso reconstruir con alguna verosimilitud la información que pudo poseer Cernuda sobre el tema; y luego, examinaré qué elementos inductores, dentro de ese complejo paisaje cultural, pudieron actuar sobre el título y el "sistema" poético de Cernuda. Ni qué decir tiene que mi propuesta de trabajo, en ambos aspectos, es aproximativa y no pretende agotar el tema, sino abrirlo a nuevas perspectivas de lectura. Aunque no esté muy seguro de lograrlo.

Tal vez la primera noticia, o el primer encuentro de Cernuda con el personaje, se lo deparara un breve artículo de José Ortega y Gasset, "Oknos el soguero", que apareció primero en Revista de Occidente (agosto de 1923) ${ }^{3}$. En él reseñó Ortega la reedición en Alemania del ensayo del mismo título, Oknos der Seilflechter, de J.J. Bachofen, mitólogo y pionero de los estudios de antropología hermenéutica. El ensayo formaba parte originariamente de una de las obras fundamentales del maestro alemán: Versuch über die Gräbersymbolik der Alter (Base1, 1859) ${ }^{4}$.

Ortega, tras elogiar en Bachofen al descubridor de la idea del matriarcado en la antigüedad a partir preferentemente de imágenes arquetípicas procedentes de testimonios funerarios (no en vano el ensayo se inserta en un libro titulado "Simbólica sepulcral de los antiguos") resume y comenta

3. Recogido luego por Ortega en su libro Espíritu de la letra (1927) y en Obras Completas, Madrid, Alianza Editorial, 1983, t. III, pp. 593-9. Las citas corresponden a esta última edición. No es de extrañar, dada la antipatía que mostró siempre Cernuda hacia Ortega, que no mencione nunca el artículo de éste, "Oknos el soguero". Salvo en una ocasión: en un fragmento tachado al final del borrador manuscrito (conservado en los archivos familiares de Sevilla) del citado texto para las guardas del tercer $O c n o s$, con la única antención de despejar las confusiones en que incurrían aquellos críticos ignorantes que mencionaban su libro con la grafía, más común, del artículo orteguiano, junto a otros errores un tanto pintorescos como lo de "Oknos, el alfarero" (un recuento de éstos, y no sólo para Ocnos, se halla en la nota de Carlos Peregrín Otero, "Indígenas y extranjeros sobre Cernuda", Homenaje a Luis Cernuda, La Caña Gris, Valencia, Otoño 1962, pp. 109 111).

4. He utilizado la edición de Bachofen a que hace referencia el artículo de Ortega: Oknos der Seilflechter. Ein Grabbild. Erlösungsgedanken Antiker Gräbersymbolik, herausgegeben und eingeleitet von Manfred Schroeter, München, Oskar Beck, 1923. Parte de este ensayo se halla, con otros importantes textos del maestro alemán, en la reciente selección debida a Andrés Ortiz-Osés y trad. de Begoña Ariño: Mitología arcaica y derecho materno, Barcelona, Anthropos, 1988, en especial pp. 185-194 y, también, 39-51. 
la significación ritual y arcaica que otorgó a Ocnos el mitólogo alemán. Para éste, los símbolos en los que se expresa la humanidad primigenia poseen un significado fundamental de orden físico natural; y a partir del momento en que este sentido se pierde, cuando ya no tiene vigencia la concepción vital de la que aquéllos emanaban, la comunidad crea explicaciones racionales que los desvirtúan. Así, el sentido profundo, simbólico, que suscita la figura de Ocnos (ese "viejo taciturno", según lo califica Ortega), mal se acomoda a las toscas interpretaciones tardías de un Pausanias o de un Plinio para quienes, respectivamente, Ocnos sería el hombre laborioso malogrado por una mujer-asno dilapiladora, o un holgazán condenado a repetir una tarea inútil en los infiernos. Bachofen sitúa en cambio a Ocnos en relación con una antigua ceremonia egipcia, según es relatada por Diodoro, en la que un iniciado trenzaba una soga mientras los demás iban destruyéndola por el extremo contrario ${ }^{5}$. La labor constante de Ocnos, combinada con la acción contraria del animal, responde a un modelo arquetípico, el mismo que fundamenta el tejido que labora Penélope. Y Bachofen recuerda el simbolismo semejante que ofrece en los misterios órficos el huevo orginario, cuyos dos colores, blanco y negro o rojo, se transforman de continuo uno en otro, como ocurre con la vida y la muerte y el día y la noche. En realidad, dice él, "ningún pensamiento ha sido tan diversamente expresado en la antigua simbólica y mitología como éste que ahora nos ocupa", el de expresar y celebrar la doble fuerza, creadora y destructiva, que rige la vida de la naturaleza ${ }^{6}$. Y Ortega resumió así, de acuerdo con la interpretación de Bachofen, el sentido de Ocnos:

Lo que Oknos laborioso trenza, el asna lo va anulando. Representa este animal el poder destructor necesario al ritmo de la Gran Madre. Una creación lograda y perfecta detendría el proceso: es menester que colabore la potencia enemiga, la energía destructora. El trozo de soga que hay entre las manos del soguero y el belfo de la bestia es breve jornada de la existencia que se abre entre el poder de hacer y el de deshacer, ambos eviternos.

La mención aquí de la "Gran Madre" responde al otro aspecto fundamental del pensamiento de Bachofen: el trasfondo matriarcal-naturalista que él halla en los elementos que concurren en el mito de Ocnos. El trenzar como el hilar o el tejer, es una actividad que remite a una labor de la Madre Naturaleza, y la presencia de lo no cultivado (la ciénaga) y de plantas pantanosas (el junco, el esparto) nos sitúa simbólicamente en una cultura preagrícola y en un régimen de vida ginecocrático: "el esparto - sintetiza Ortega - no es, como el cereal, obra del hombre; el spartum tiene la misma

5. J.J. Bachofen, Oknos der Seilflechter, ed. cit., pp. 23-4. Cfr. asimismo la nota de J.G. Frazer a su traducción de Pausanias: Description of Greece, London, MacMillan, 1913, t. V., pp. $377-8$.

6. J.J. Bachofen, Mitología arcaica y derecho materno, ed. cit., p. 46. 
raíz y sentido que spurius, sin padre". Y en términos dramáticos, de acuerdo a una propensión enfática innata, Ortega expresa el triunfo a la larga del ordo patriarcal sobre las formas de matriarcado, el relevo de la cultura ctónica por la uraniana: "Aún tardará en llegar Apolo, representante de una cultura masculina, portadora de luz y alegría. Oknos y todo el repertorio de objetos en su derredor pertenecen a la inspiración triste y tenebrosa de la caverna telúrica. La lucha debió ser gigantesca entre los dos poderes: el útero cavernoso y arcano, el falo que inicia la ascensión hacia los dioses del sol y del rayo, hacia una cultura solar y fulgural". Pero estas palabras no son en realidad sino una glosa a lo dicho por Bachofen en el penúltimo capitulillo de su ensayo. Precisamente, para subrayar por contraste el simbolismo originario de Ocnos, concedió una gran importancia a una representación funeraria tardía, en Villa Panfilia (Roma), excepcionalmente plácida y serena, del soguero. En ella no vemos al laborioso anciano ocupado en una estéril labor sino tranquilamemnte reposando de su trabajo; y el escenario no es el Hades, donde suele figurársele en la mayor parte de las versiones, sino un pacífico paraje, a cielo abierto y a la sombra de árboles, como rodeado del gozo de la creación. Tal imagen "representa la máxima espiritualización de un símbolo", a juicio del alemán; se trata de otra perspectiva expresivamente opuesta a la representación tradicional: el personaje telúrico-infernal asciende hacia la luz, "Ocnos el sufridor se ha convertido en el Ocnos libre", concluye Bachofen".

El plano antropológico-hermenéutico aplicado al mito de Ocnos era lo que más ocupaba al alemán, como a su comentarista español, y es natural por tanto que en general desestimara las referencias escritas que, por tardías, contenían interpretaciones desviadas, según Bachofen, de su fundamento físico-material. Las versiones cambiaban. Ya vimos cómo la representación de Villa Panfilia resaltaba ideas de paz y redención que no correspondían al posible retrato genérico (como el que trazó Bachofen) de un "anciano soguero siempre laborioso" cuya "actividad estéril, vana, constituía su ser más profundo". Sin duda el mịto de Ocnos sufrió con el tiempo cambios y transformaciones, pero los elementos que concurrieron desde antiguo en él fueron probablemente (o al menos así nos han llegado) más oscuros y enredados de lo que supuso a mediados del siglo pasado, en beneficio de su brillante interpretación, Bachofen. Ante unas versiones tan lacónicas como distintas y a veces contradictorias unas con otras (insistiremos algo en ello a propósito del texto de Pausanias), otros tratadistas han llegado a dictaminar que "el verdadero sentido de la leyenda de Ocnos se nos escapa" (Pierre Grimal, Dictionnaire de la mythologie).

La documentación clásica sobre el tema contiene, además de una media docena de representaciones en el arte antiguo, una serie de breves testimonios literarios. Aunque en las páginas del libro que acabamos de comentar

7. J.J. Bachofen, Ibid., p. 186; corresponde al original Oknos deer Seilflechter, ed. cit., p. 13. 
(y de modo muy rápido en la nota de Ortega) se mencionan estas referencias básicas greco-latinas, no es necesario suponer, ni siquiera es probable, que Cernuda acudiera a un tratado tan especializado, y escrito en alemán, como el de Bachofen. Además, es lógico que la información directa e indirecta sobre el tema fuera pasando de libro en libro. Sugiero que Cernuda bien pudo consultar en Glasgow las eruditas notas que había elaborado J.G. Frazer - el célebre autor de La rama dorada - para su traducción inglesa de Pausanias (Description of Greece, London, MacMillan, 1913, tomo V). La información que da Frazer sobre la descripción de las perdidas pinturas de Polignoto es amplia, ordenada y sintética; pero, eso sí, omite una vez más (al igual que el libro de Bachofen sobre Ocnos) toda mención al ensayo de Goethe, al que ni siquiera cita en la larga lista bibliográfica de estudios del XIX, casi sin excepción en alemán ${ }^{8}$.

Pasemos ahora a la fuente clásica más difundida. El perdido conjunto pictórico que realizó Polignoto en el Lesque de Delfos sólo se conoce gracias al testimonio escrito de Pausanias, en su obra Descripción de Grecia, en el siglo II de nuestra era. Nos interesa la descripción literaria del cuadro titulado "Descenso de Odiseo al Hades" (Descripción..., X, 28-31). Dicho cuadro pertenecía al género llamado Nekyia, sobre la evocación del país de los muertos, que ya aparece en un episodio bien conocido de La Odisea (canto XI). Los tratadistas discuten hasta qué punto alteró Pausanias, pese a su voluntad de ser lo más fiel posible a su fuente pictórica, el contenido de Polignoto, y ello no sólo por el lógico deterioro de la propia pintura durante los cuatro o cinco siglos que mediaron entre la labor del artista y la del escritor - lo cual, según confiesa éste, en ocasiones dificultaba seriamente su trabajosino por el aprovechamiento por parte de Pausanias de la nueva información o de las especulaciones sobre los personajes tratados. Por otro lado, la descripción de Pausanias fue, aunque breve, tan completa y precisa que originó, desde mediados del siglo XVIII, una serie de hipotéticas reconstrucciones de las pinturas perdidas; y bien pudo ocurrir que esas "versiones" gráficas hubieran influído sobre algunos comentaristas, especialmente cuando éstos intentanban interpretar (por ejemplo, Goethe) la intencionada disposición y la interrelación topológica de las figuras en el cuadro.

El pasaje de Pausianas sobre Ocnos, en la traducción de Antonio Tovar, dice así:

Después hay un hombre asentado que según la inscripción es Ocno. Está trenzando una soga y a su lado está una burra que se va comiendo lo ya trenzado. Dicen que este Ocno era un hombre laborioso, pero que tenía una mujer gastadora y cuanto ganaba trabajando era en seguida dilapidado por ésta. A la mujer de este Ocno dicen que alude Polignoto. Pero también sé que los jonios cuando ven a alguien traba-

8. J.G. Frazer, en su traducción de Pausanias, Description of Greece, ed. cit., V, pp. 360 y 378. 
jando inútilmente dicen que tuerce la soga de Ocno.

Los agoreros llaman ocnos a un pájaro, la mayor y más hermosa de las garzas reales y de las más raras de todas las aves ${ }^{9}$.

Esta versión de Pausanias, que es la más difundida entre las existentes, plantea no pocas incógnitas, en parte debido a que lo que empezaba siendo una descripción acabó convirtiéndose en un acopio de noticias revueltas, recogidas acríticamente por el autor, a partir de lo que se sabía o lo que se creía sobre Ocnos. Así, la vaga forma verbal "dicen" introduce sin más una explicación misógina como causa de la situación, la mujer despilfarradora: especulación al parecer tardía pero que se ha venido repitiendo comúnmente (así aparece, por ejemplo, monótonamente en la mayoría de las enciclopedias); en tanto que el proverbio jonio a que alude inmediatamente después nos sitúa en el plano de una tradición oral, posiblemente más arcaica que la otra, e introduce una explicación mucho menos anecdótica, más general o propiamente simbólica: el trabajo estéril. Los estudiosos discuten otros puntos de la versión de Pausanias. Salomon Reinach apunta a la posibilidad de que Polignoto, apoyándose en una tradición iconográfica, se hubiera inspirado en el cuento jonio de Ocnos; y señala que existió otra versión, acaso más antigua e independiente de aquélla, que él ve representada en un vaso (lekythos), donde no hay indicación expresa de cuerda o soga sino que esquemáticamente, mediante unas simples líneas paralelas, se sugieren unos caídos haces de leña, mientras un hombre sentado los observa sin aparente intención de recogerlos, y detrás de esta figura está arrodillada su burra. En relación con esta última representación recuerda Reinach un pasaje de El asno de oro de Apuleyo (IV, 18) en el que Psique se dispone a descender a los infiernos y alguien la conmina a que no atienda los posibles requerimientos de algún arriero cojo que vaya con su asno para que le ayude a transportar los caídos haces de leña ${ }^{10}$. El asno, en estos episodios concretos, desempeña una función poco relevante. De hecho, en una versión probablemente relacionada con las anteriores y todavía más alejada de la leyenda central de Ocnos, se prescinde totalmente del animal. Se trata de la fábula 78 de Esopo, "El viejo y la muerte". En ella el viejo es un caso de flaqueza moral, de total falta de resolución: cansado de cargar leña, deja su fardo y reclama la Muerte, pero cuando ésta le pregunta el motivo de su demanda el anciano le contesta que para que le libere de la carga. El relato podría ser ambiguo si se entendiera también, con sentido simbólico, que la carga es la vida y que por tanto lo que el viejo requiere es su muerte, pero

9. Cito por la traducción de Antonio Tovar: Pausanias, Descripción de Grecia, Valladolid, Facultad de Filosofía y Letras, 1946, pp. 716-7.

10. Véase Salomon Reinach, "Sisyphe aux Enfers et quelques autres damnés", en Revue Archéologique, París, 4a serie, I, enero-junio 1903, p. 185 (tratan sobre Ocnos las pp. 184-8). Dicho ensayo lo recogió Reinach en el tomo II de su obra Cultes, mythes et religions, París, E. Leroux, 1909, pp. 159-205 (sobre Ocnos, pp. 189-193). 
Esopo es bien explícito en cuanto a su lección moral: mostrar el apego que aun el hombre más miserable tiene a la existencia ${ }^{11}$. Sin entrar aquí en la consideración de esta familia de versiones, ni menos aún en las dificultades que plantea explicar su entronque histórico con las otras, llama la atención que se sugiera aquí, en nítido contraste con el atributo de actividad tenaz aunque infructuosa - comúnmente señalado por Pausanias y otros-, un rasgo de desgana o fatiga. Plinio (Naturale historia, XXXV, 137), refiriéndose claramente a nuestro personaje (pues éste en las historias de Apuleyo y Esopo no tiene nombre propio), fue taxativo: la pigritia en vida que fue constitutiva de Ocnos es lo que explica su condena a repetir para siempre, tras su muerte, un trabajo estéril. Una interpretación que, como vemos, contrasta con la de Pausanias: el castigo no es por culpa de la mujer-asno sino por una debilidad del propio hombre. Pero lo que aquí me interesa es destacar la coexistencia de dos familias de versiones tan opuestas y el hecho de que la segunda, la de un Ocnos desganado, aunque parezca más lateral que la otra, venga expresivamente refrendada por el propio significado principal de la palabra griega, que es la pereza, hasta el punto de que el erudito Frazer, en su mencionada traducción inglesa de Pausanias, eligió para el nombre propio "Ocnos" el abstracto personificado "Indolence". Es más, Frazer nos informa en una nota acerca del último sentido aducido por Pausanias -el que fue dado por los agoreros a una variedad de la garza real - que, según una fábula contada por Aristóteles, el ave en cuestión contaba con antepasados que habían sido hechos esclavos y, en consonancia con su nombre (oknos), era el pájaro más perezoso de su especie ${ }^{12}$.

Pasemos ahora al artículo de Goethe, Polygnots Gemälde in der Lesche $z u$ Delphi, cuya fuente directa fue Pausanias. Goethe lo concibió y redactó como reseña de una exposición de dibujos celebrada en Weimar en 1803 y como orientación para un concurso de 1804 , también sobre el tema de las pinturas de Polignoto en el Lesque de Delfos. Lo publicó como introducción en una hoja plegable y luego lo recogió en la Jenaischen Allgemeinen Zeitung (primer trimestre de 1804$)^{13}$. He aquí el contenido de este trabajo.

11. A esta fábula alude, sin nombrarla, el mitólogo Ulrich von Wilamowitz Moellendorff, para explicar, de forma un tanto extraña por unilateral, la condena de Ocnos: Der Glaube der Hellenen, Darmstadt, Wissenschaftlische Buchgesellschaft, 1973, t. II, p. 181 (el libro fue publicado póstumamente en 1959). La fábula de Esopo sí se menciona explícitamente, en relación con la hipótesis de Wilamowitz en el célebre diccionario Pauly sobre la antigüedad clásica: véase la entrada "Oknos" en Der Kleine Pauly. Lexikon der Antike in fünf Bänden, München, Deutscher Taschenbuch Verlag, 1979, t. 4, p. 271.

12. J.G. Frazer, en su mencionada traducción de la obra de Pausanias, Description of Greece, t. I, p. 542, y t. V, pp. 378-9.

13. Para una más detallada información sobre las circunstancias en que Goethe compuso y publicó su ensayo, remito al artículo de Horst Nahler, "Goethes Aufsatz über Polygnot", en Neue Folge des Jahrbuchs der Goethe-Gesellschaft, t. 28, 1966, pp. 93-105. La paginación para el ensayo de Goethe corresponde a la edición consultada que indico en la nota 2. 
Primero describe, sin apartarse de Pausanias, los tres grandes cuadros de Polignoto: "Conquista de Troya", "Glorificación de Helena" y "Descenso de Odiseo al Hades"; caracteriza luego brevemente el estilo de Polignoto, en relación con otras representaciones pictóricas en ánforas, y retoma e interpreta por su cuenta los tres cuadros mencionados en los que ve, respectivamente, un predominio de valores histórico, simbólico y poético; y por fin, en el último apartado del ensayo, expone cierto proyecto pedagógico, tratando de definir su propio papel como mediador, entre el erudito y el artista, con vistas a contribuir a reimpulsar el arte en Alemania.

"Descenso de Odiseo al Hades" poseía según Goethe "un alto sentido poético"; es el cuadro que más le interesaba. Lo describió primero con gran detalle, siguiendo punto por punto el relato informativo de Pausanias (pp. 93-100), para luego comentarlo "según nuestros propios criterios", es decir, "olvidando por un tiempo" su fuente y modelo (pp. 110-116). Nos importa, naturalmente, esta última sección, donde el autor apunta comentarios y esboza el retrato moral de algunos personajes, aisladamente o por grupos, de acuerdo a su situación y a la interrelación que, según él creyó descubrir, guardaban en el cuadro. Este, para Goethe, ofrecía tres espacios superpuestos, a modo de engranaje articulador. Así, el pintor habría situado intencionadamente a Odiseo y sus compañeros en la parte superior debido a que, "según los poemas homéricos, Odiseo no desciende hasta el Hades mismo, sino que se aventura sólo hasta sus lindes" (p.112). No es necesario seguir, paso a paso, la revisión que hace el cuadro de acuerdo a una intencionada o simbólica disposición. Para nuestro objeto importa destacar únicamente algo sobre lo cual él mismo insistió: el contraste entre los grandes héroes, agrupados por afinidad, que figuran en el centro de una escena del Hades, y los grupos de los lados compuestos por seres abrumados a causa de la inutilidad de sus empeños. Y este contraste del centro y los lados se completa en el caso de estos últimos con otra oposición fundamental: los penitentes homéricos Tántalo y Sísifo, en un extremo, frente a Ocnos y su burra que están situados en el otro. El parentesco entre los componentes de esta última oposición se hallaba, a lo sumo, ya implícito en el cuadro de Polignoto y el relato de Pausanias ${ }^{14}$. Constituye sin duda una novedad del ensayo de Goethe el hecho de que se fijara en las particularidades de tal relación y las recalcara: de un lado ofrecen un rasgo compartido, el ser representación del esfuerzo infructuoso, y del otro, los separa y diferencia el hecho de que mientras Tántalo y Sísifo son encarnación trágica de lo que Goethe llama el "más terrible de los destinos humanos", Ocnos es sólo la versión "ingenua" de un símbolo profundo. Erich Rohder, que sí parece que conoció el ensayo de Goethe que comentamos, no sin temeridad fue mucho más lejos en el rebajamiento de nuestro personaje, pues, basándose en una supuesta (en realidad nada probable o remotísima) alusión a Ocnos en un pasaje de Las ranas

14. Pausanias, Descripción de Grecia, trad. de Antonio Tovar, ed. cit., pp. 722-3 (sobre Sísifo y Tántalo). 
(verso 186) de Aristófanes, consideró taxativamente al soguero como "una parodia, burlesca en parte y en parte melancólica, de las figuras de Sísisfo y de Tántalo, pintadas por Homero, réplica burlesca de aquella aristocracia homérica de enemigos de los dioses cuyas penas simbolizan, como decía Goethe, el vano afanarse eternamente" 15 . De todos modos, la razón inmediata y determinante de que se viera a Ocnos como una réplica paródicoburlesca o, según estimaba Goethe, "ingenua" y sin registros trágicos, no es otra que la referencia misógina a un prototipo de mujer derrochadora, lo cual es, según vimos, la explicación tradicional más común de la labor eștéril de Ocnos desde que Pausanias la admitió como cierta.

- Transcribamos ahora íntegramente (puesto que no existe hasta el momento traducción en castellano ${ }^{16}$ ) los pasajes del ensayo de Goethe sugeridos por Ocnos, entre los cuales se encuentran las líneas que Cernuda eligió como lema para su libro:

[...] Muchos más comentarios nos sugiere el extraño grupo en el que una burra va devorando el trabajo de un diligente soguero.

Los antiguos parecen haber considerado-y con razón- un esfuerzo infructuoso como el mayor de los tormentos. La roca de Sísifo, que vuelve a rodar siempre hacia abajo, los huidizos frutos de Tántalo, el llevar agua en cántaros rotos [alusión a las Danaidas] son elementos que apuntan todos a objetivos no alcanzados. No se trata aquí de una represalia ni de un castigo específico adecuados al delito. No, estos infelices son todos abrumados con el más aterrador de los destinos humanos: ver fracasar el objetivo de un empeño serio y persistente.

Lo que es allí pensado como castigo de violentos titanes y otros culpables, aparece aquí representado de la forma más ingenua como un destino o un estado mediante las figuras de Ocnos y su burra. Trenzar es tan natural para él como para ella lo es comer; él podría dejar de trenzar, pero ¿qué haría entonces? Prefiere trenzar por trenzar, y el junco, que también hubiera podido ser devorado sin trenzar, es comido una vez trenzado. Acaso tenga así más sabor o resulte más alimenticio. Podría decirse que el tal Ocnos encuentra de este modo una especie de entretenimiento con su burra.

Pero al encomendar a nuestros lectores la explicación ulterior de este profundo símbolo, nos limitaremos a observar que el hombre griego, que miraba directamente a la vida, creyó descubrir aquí el caso de un hombre trabajador que tiene por compañera a una mujer

15. Erwin Rohde, Psique. El culto de las almas y la creencia en la inmortalidad entre los griegos, trad. de S. Fernández Ramírez, Barcelona, Labor, 1973, t. I, pp. 299-300.

16. Agradezco al traductor Juan José del Solar su ayuda y amabilidad al traducir, expresamente para este trabajo, los pasajes que a continuación transcribo del ensayo de Goethe Polynots Gemälde in der Lesche zu Delphi. Asimismo aprovecho la oportunidad para agradecer a otro amigo, el joven helenista Francesc Casadesús, el interés con que revisó el contenido de estas páginas sobre el mito de Ocnos y su aportación de nuevos textos, y sugerencias de sumo interés, para mi trabajo. 
dilapiladora (pp. 113-4).

Al final de cuadro advertimos aún aquel grupo de personajes que se esfuerzan en vano $y$, a decir verdad, nos dan a conocer el lugar en que nos encontramos. Se nos presentan aquí Sísifo, Tántalo y otros innominados que habían descuidado su iniciación en los grandes misterios. Si Ocnos aún podía hacernos sonreír, los motivos de representaciones similares están aquí intensificados en un registro trágico. En ambos extremos del cuadro encontramos personajes que se esfuerzan en vano y, dentro de esos estados desconsoladores, grupos de héroes y heroínas apiñados y cercados (p. 116).

Ya señalamos que para Goethe este cuadro poseía un alto sentido poético. Cabe preguntarse la razón específica de ello. Tal vez se deba a la tensión -sólo expresada gracias a la mano del artista- entre el signo temporal que rige las acciones del hombre sobre la tierra y la eterna existencia que gozan en el Hades. No olvidemos que el Hades no era fundamentalmente para los antiguos, como lo fue el infierno para la fantasía cristiana, una representación de los horrores y los suplicios eternos, sino más bien un "cuadro" o figuración de los muertos en la otra vida y, al menos aquí para Goethe, como un espejo imperecedero de la presente. En realidad, las relaciones de afinidad que él destacó reproducen las situaciones más habituales de la vida, ahora atenuadas pero permanentes, que llevaron los personajes en la tierra. Goethe señala las analogías entre uno y otro espacio, y así vemos cómo las figuras siguen reunidas y ocupadas en los mismos trabajos y sentimientos que antes: "Foco e Isaeo, ocupados con un anillo, el signo más tierno de la amistad; Acteón y su madre, participando con idéntico placer en la caza; Mera, solitaria entre ambos, podría parecer enigmática si una afectuosa inclinación por su padre no le hubiera asegurado aquel puesto entre los graciosos e ingenuos amantes [...] Orfeo, como esposo fiel, reposa sobre la tumba de aquella a quien perdió dos veces" (p. 115), etc. etc. De esta forma, Goethe revive y recrea imaginariamente la actividad final que tal vez más define y caracteriza a los habitantes del pasado que admira, y éstos gozan, gracias a la muerte y a la celebración del arte, de una fijación eterna, de una especie de inviolabilidad:

Entre los muertos todo es eterno - así concluye Goethe su comentario- El estado en que el hombre se presentó por última vez a los habitantes de la Tierra queda fijado por todo el futuro. Viejo o joven, bello o desfigurado, feliz o infeliz, flotará siempre ante nuestra imaginación sobre el lienzo gris del Hades (p. 116).

¿Sería excesivo adivinar, detrás de este nuevo y a ratos exaltado descenso al Hades realizado por Goethe bajo la modesta guía de Pausanias, una manifestación más de esa "poética" de la muerte a que tan instintivamente tendieron los románticos? 
Pero es hora ya de examinar cuál fue la forma de "entender" el mito por parte de Cernuda, qué es lo que explica su interés por él, y comentar qué papel, sin duda difuso, guarda el título "Ocnos" en relación con el contenido del libro. Para ello recapitulemos antes algunos rasgos conformadores del mito, teniendo en cuenta el entramado de versiones, a veces tan disímiles, que se han ido sucediendo: 1aa actúa en él, permanentemente, una doble fuerza positivo-negativa, creadora-destructora, lo que en estimación de Bachofen respondería a su simbolismo original, el de reproducir el proceso de lo natural; $2^{\circ}$, la actividad de Ocnos, tan tenaz como inútil, expresa, según el proverbio jonio aducido por Pausanias, una laboriosidad estéril; $3^{\circ}$, a Ocnos se le suele situar en el Hades, asociado a otros penitentes del esfuerzo infructuoso (Sísifo, Tántalo...), pero junto a este Ocnos sufridor figura también, más excepcionalmente, un Ocnos libre, tal como aparece en la visión plácida y positiva de Villa Panfilia; 4ำ coexiste, junto al Ocnos laborioso, otra versión de un Ocnos indolente, sugerido por el sentido principal del término en griego y que se halla igualmente documentada en la antigüedad; y $5^{\circ}$, aunque para explicar la condena de Ocnos se dieron dos razones correspondientes a su doble faceta de laboriosidad e indolencia - la más difundida de Pausania que equipara el asno a una mujer derrochadora, y la de Plinio, que atribuye la condena a la pereza culpable del personaje-, parece, según la opinión de Pierre Grimal y otros especialistas, que la antigüedad no logró dar una genuina razón del castigo de Ocnos.

Resulta curioso que a veces se entremezclen y actúen conjuntamente versiones y explicaciones tan distintas en un mismo autor. Así, según vimos, Pausanias, en un brevísimo retrato, da cabida a la anécdota misógina supuestamente explicativa del sufrimiento de Ocnos, al proverbio jonio que potencia la dimensión del soguero como exponente de una vana laboriosidad $y$, por último, al uso del término que hacían los agoreros, uso que aludiría, si se atiende a cierta fábula que cuenta Aristóteles, a una hermosa garza con atributos de indolencia y pereza. Y todavía Goethe, al aceptar lo de la mujer-asno, permite que esa tosca especulación determine su propia interpretación matizadamente degradada de Ocnos.

Por cierto que en la traducción que propone Cernuda del pasaje de Goethe resalta una infidelidad reveladora: Eselin, en alemán, es burra o asna, femenino, y no asno, según traduce Cernuda, en masculino con sentido genérico de esa especie animal. Es evidente que a Cernuda no tenía que interesarle la explicación circunstanciada acogida por Pausanias. Cabe, pues, considerar este cambio como una voluntaria infidelidad, en lugar de un simple error o un descuido del traductor, porque esto último supondría aceptar que Cernuda ignoraba la vieja y difundida especulación que imponía el uso del femenino, y ello resulta más que improbable. De todas formas, a uno le hostiga inevitablemente la pregunta de si Cernuda tuvo realmente acceso al comentario íntegro de Goethe sobre el cuadro "Descenso de Odiseo al Hades", es decir, al contexto de la cita. Mi opinión, aunque no sea concluyente, es que sí lo conoció; y sin embargo creo también que lo 
aprovechó muy parcialmente. Fijémonos, por ejemplo, en la oposición establecida por Goethe (por supuesto que no recogida por Cernuda) entre Ocnos y el grupo de penitentes homéricos. Ello entraña, como dijimos, cierta degradación de aquél, pero de una forma suave y atenuada si la comparamos con la opinión claramente rebajante y burlesca que merece el personaje a Erwin Rohde. Ese Ocnos de Goethe, "ingenuo" y "que hace sonreír", pero que guarda todavía conexión con el símbolo del que es originariamente expresión, no dejaba de cuadrar del todo con el matiz irónico, de indefinido fracaso, que envuelve al ser invocado por Cernuda: más que el titán homérico -el condenado grandioso, trágico y algo teatral- prefería él sin duda a un Ocnos más modesto, sufridor y libre a un tiempo, personaje de un desaliento y una amargura más gris y como en sordina, menos marcado y enfático. Así, uno de los aspectos de la atracción de Cernuda hacia Ocnos sería precisamente su borrosa y doble faz que permite adivinar, bajo un afán de absoluto, el límite del ser mortal.

Pero Ocnos contaba asimismo con otros méritos para atraerle y convertirse para él en una figura de proyección e identificación. Destaco uno: la ambivalencia que expresivamente le acompaña, según nos ha legado la tradición, de una tenaz laboriosidad y el rasgo no menos sustancial, por su base linguística, de indolencia y desgana (recuerdo aquí lo observado, en páginas anteriores, sobre la traducción expresa que hace Frazer de Ocnos por Indolence). Una tensión y una polaridad de elementos connaturales a Cernuda: impulso cierto y difuminada dejadez. Pero sigamos. El rasgo más permanente y diríase que el atributo propiamente más constitutivo del mito, aquel que cimenta el motivo tantas veces invocado para el soguero del esfuerzo infructuoso, es la presencia de dos principios contiguos y enemigos, creador uno y devorador el otro: "Cosa tan natural era para Ocnos trenzar sus juncos como para el asno comérselos", empieza la cita goetheana elegida por Cernuda. Es inevitable asociar esta dualidad con otras que conforman el sistema poético cernudiano, empezando por la expresada en el título que eligió para su poemario conjunto, o por la que implica su noción de "deseo" (frente a la correlativa de "amor") cuyo carácter absoluto excluye la posibilidad de realización. Y tal vez sea oportuno, aunque no sea más que para salir velozmente de un terreno tan frecuentado al hablar de Cernuda, recordar aquí la confidencia que según Gil-Albert le hizo en Valencia durante la guerra, acerca de su preferencia por el conocido episodio mítico de Apolo persiguiendo a la ninfa Dafne, que al ser alcanzada se le convertía en laurel: también, "al hombre se le transforma, en sus manos, todo lo que ve, lo que posee; no consigue nunca sino apresar algo distinto de aquello que anhelantemente buscó. Penetrado por el estilete de esta última intuición, el suceso clásico adquiría una fatalidad reinante que no daba pie a ninguna esperanza"17.

17. Juan Gil-Albert ha contado tres veces esta confidencia que le hizo Cernuda: "Fecha conmemorativa", La Caña Gris, otoño 1962, pp. 26-7; Memorabilia, Barcelona, Tusquets, 1975, p. 
Más preciso en relación con nuestro objeto es el interés de Cernuda por otro mito, el de Marsias (que aparece en una página de El banquete de Platón $\mathrm{y}$ al que reencontramos también, al descender con Odiseo al Hades, en los relatos de Pausanias y Goethe), un mito en fin asociado en algún momento por Cernuda al proyecto de Ocnos. De él nos dejó un breve texto, fechado en 1941, que recogió mucho después en el tomo segundo de Poesía y literatura $^{18}$. El Marsias de Cernuda es, más claramente aún que Ocnos, una figura de proyección: trágica figuración del afán sobrehumano del poeta. Es el joven que de una zampoña hecha de "sutiles cañas entrelazadas" logra extraer un son desconocido, capaz de brindarle al principio un deleite total al que no es ajena la posibilidad de un reconocimiento de sí mismo, pero que más tarde, ante el deseo de comunicarlo a los demás, va sintiendo un desasosiego que lo trastorna: "A veces llegó a maldecir al maligno instrumento causa de todo. Pero no podría arrojarlo de sí, porque era ya parte suya, y con su aliento había pasado a él su espíritu mismo". Luego evoca Cernuda cómo Marsias desafió públicamente a Apolo y cómo de sus labios "brotó la melodía doliente y pura, con un temblor oscuro que la del dios no tenía". Los miembros del jurado, sin embargo, "injustos porque no entendían y porque eran serviles", optaron por premiar a Apolo, quien ordeno el desollamiento de Marsias. Hay ciertos elementos de parentesco entre este mito y el de Ocnos según los tratadistas, como su común tenebrosidad frente a la claridad apolínea. Bachofen evoca a Marsias a propósito del maleficio de la materia de su instrumetno músico, en su ensayo sobre el soguero; Ortega se hace eco de ello y comenta: "La caña, hija del cieno, es siempre trágica, y dondequiera hay oscura tragedia, germina o suena [...] La flauta vegetal vuelve a ser trágica en Marsias"19. Y también, en una línea de interpretación simbólica y ritual, los mistagogos del Renacimiento tendieron a comentar el desollamiento de Marsias en términos de una ceremonia purificadora, mediante la cual, según el historiador Edgar Wind, "la fealdad exterior del hombre era desgarrada y se ponía al descubierto su belleza interna"; y más adelante: "Para obtener el amado laurel de Apolo, el poeta debe pasar por la agonía de Marsias"20. Pero Cernuda en este breve texto - de valor más declarativo que propiamente poético- da otro giro

233, y "Realidad y Deseo de Cernuda. Visión de un contemporáneo", en Luis Cernuda, Publicaciones de la Universida de Sevilla, 1977, p. 96.

18. Luis Cernuda, "Marsias", en Prosa Completa, ed. cit., pp. 1089-1093. El relato de Cernuda es una recreación a partir de las versiones tardías y más desarrolladas en la literatura clásica del tema, en especial las debidas a Diodoro Sículo (La biblioteca de la historia, libro II, 59) y Ovidio (Metamorfosis, libro VI vv. 380-402), para lo referente a la disputa con Apolo y al desollamiento de Marsias, respectivamente.

19. J. Ortega y Gasset, "Oknos el soguero", Obras Completas, ed. cit., III, p. 598.

20. Edgar Wind, Los misterios paganos del renacimiento, trad. de J. Fernández de Castro y J. Bayón, Barcelona, Barral Editores, 1972, pp. 175 y 176. En Cernuda, no es el "amado laurel" prometido a Marsias sino un destino fatal lo que parece exigir del poeta su agonía y muerte. Tal vez 
interpretativo, sin duda aproximando a su situación personal el motivo del desollamiento, que se vuelve pretexto para una declaración de principios sobre el destino y la derrota final del creador. Como escribe James Valender, "el sufrimiento de Marsias es cifra de las dudas que tiene el poeta o el artista con respecto al valor de su obra", dudas que parecen provenir de dos fuentes: por una parte, de la naturaleza ambiciosa de la tarea del poeta ("venciendo su limitación mortal" dar expresión a "un afán sobrehumano"); y, por otra, de la falta de comprensión con que el público acoge su traba$\mathrm{jo}^{21}$. Y el breve texto de Cernuda termina así:

Así, pues, y en las menos palabras, ¿qué se cifra simbólicamente en ese mito de Marsias? Que el poeta debe saber cómo tiene frente de sí a toda la creación, tanto en su aspecto divino como en el humano, enemistad bien desigual en la que el poeta, si lo es verdaderamente, ha de quedar vencido y muerto.

Resuena sin duda lo dicho aquí a un pasaje de contenido mucho más complejo de Palabras antes de una lectura sobre las "causas hondas" del "fatalismo" del poeta y la doble lucha que éste debe sostener contra el ambiente social y contra fuerzas invisibles ${ }^{22}$. Y asimismo, la conclusión de "Marsias" guarda un paralelismo con el mencionado pasaje rememorativo para la tercera edición de Ocnos, cuando Cernuda dijo que halló "cierta ironía justa en dar el nombre de Ocnos como el título del libro, se tome al asno como símbolo del tiempo que todo lo consume, o del público igualmente inconsciente y destructor". En ambos pasajes, sobre Marsias y Ocnos (y también en el de Palabras antes de una lectura, dentro del entramado de su poética), se apunta a un doble conflicto coexistente pero de raíz muy distinta: uno imponderable, referido a la propia naturaleza del ser mortal en quien alienta un empeño sobrehumano, y el otro más propiamente "social".

Conviene a estas alturas plantearse la cuestión, en el fondo crucial, del momento en que el título "Ocnos" fue elegido por Cernuda para su libro. Aunque no haya - que yo sepa- constancia de ello, debió de ocurrir en

sólo así se transmute en obra la experiencia biográfica, tosca materia en que se inspira aquélla. En virtud de un acto de renunciamiento el hombre extrae lo mejor de sí mismo, poniendo al descubierto la belleza interna que ya no le pertenece. Cernuda cobra plena conciencia de ello en poemas de Como quien espera el Alba. El, que en su poesía hacía tiempo que había abandonado aquella pretensión y fe absoluta de los surrealistas de "changer la vie" por la poesía, siente, en el curso del diálogo interior del poema "Noche del hombre y su demonio", un amargo placer-expresivo oxímoron que produce el sacrificio de la vida y la entrega a la palabra-: "El amargo placer de transformar el gesto / En son, sustituyendo el verbo al acto". Sólo así en otro poema, el viejo monarca hipocondríaco puede contemplar con arrobamiento su obra, ya desprendida de sí y próximo a la muerte, una obra que es interior aunque se plasme y exprese en las piedras escurialenses ("Silla de Rey").

21. James Vaiender, Cernuda y el poema en prosa, London, Tamesis Books Limited, 1984, p. 57.

22. Prosa Completa, pp. 873-4. 
una etapa tardía o terminal de la redacción del libro. El autor, probablemente, buscaba un título sugerente, un título que no designara ni el trasfondo autobiográfico ni el escenario sevillano (tan fina y sabiamente aludido y eludido), es decir, un título que le despegara de los motivos inspiradores demasiados próximos y potenciara míticamente el libro. Todo ello en una línea semejante a su utilización en el mismo de los elementos eglógicopastoriles, en parte sustentado por la vacilante identificación del "yo" de algunos poemas con un Albanio garcilasista. Por lo demás, el título cernudiano, más que definitorio de un libro, respondería ampliamente a la situación del autor y sería especialmente ilustrativo del largo primer exilio en Glasgow. Ello explicaría la relación más bien difusa y nunca expresa que existe entre el título y el contenido específico del libro. Ni siquiera, tal como pensaba hacer con Marsias, escribió (o si lo escribió no lo publicó) un texto introductorio con su versión expresa del mismo: le bastó con estampar la sugestiva e irónica cita de su admirado Goethe.

Nuestro comentario, en consecuencia, sobrevuela un poco por el conjunto, más que sobre el libro en concreto de Ocnos. Al menos, habría motivos similares y evidentes para remitir a poemas sobre todo de Como quien espera al Alba, la sección de La Realidad y el Deseo que ocupaba a Cernuda paralelamente a la redacción de Ocnos, y naturalmente, para referirnos a ensayos literarios escritos en los mismos años, porque, nunca como entonces, la reflexión crítica estuvo en él tan conectada a su quehacer como creador. Acuda el lector al comienzo del ensayo "Poesía popular" (de enero de 1940), escrito con bronca lucidez, tras la experiencia de la guerra, donde se refiere a la animosidad encubierta que despierta en la sociedad el poeta, sin función alguna en ella, pero con "una razón fatal, anterior a su propia existencia y superior a su propia voluntad, que le lleva a escribir versos, tarea que por lo demás ni él ni los demás consideran hoy como profesión social"; y acuda también al ensayo algo posterior sobre Juan Ramón Jiménez (publicado en el 42) donde insiste sobre "la falsa situación social" del poeta después del romanticismo y con sarcasmo sugiere, como última posibilidad para aquél, la conveniencia de cierto olvido social que le permita escribir "sus versos para sí y para las dos o tres personas a quienes acaso puede aún interesar sinceramente tan sutil tarea" 23 . A la vista de estos y otros textos posibles, y pasando de nuevo a la acomodación que hizo de Ocnos, podemos notar y subrayar la curiosa sustitución de la explicación dada por Pausanias de la mujer-asno que derrochaba la fortuna del anciano soguero por la maliciosa sugerencia (un poco como si Cernuda, desde su rincón, sacara de pronto la lengua) del carácter realmente asnal del público. Si con suma facilidad completamos el símil, y el soguero que con tenacidad trenza sus juncos representa al poeta entregado a una labor absorbente, el esfuerzo infructuoso de Ocnos no es desde luego atribuíble a esterilidad e improducción (en el caso de Cernuda fueron éstos precisamente los años más fructíferos

23. Las citas corresponden, en el tomo de Prosa Completa, a las pp. 728-9 y 1342. 
de su vida); es debido a la situación de vacío, de inutilidad social y de confinamiento al limbo, que vive el poeta - si lo es verdaderamente- en el mundo moderno. Parece que esta constancia, a Cernuda, lo reforzó como poeta, y con un orgullo gemelo a su desaliento y su soledad vislumbró repetidas veces - en poemas, ensayos y cartas de entonces - algo en el fondo alentador, la idea de un lector o un poeta venideros, porque hay poetas - pensaba - que han de crear su público. Y así, con un curioso margen de esperanza, pudo decir, en confidencia a Nieves Mathews, acerca del recién publicado Ocnos: "Como es natural, espero que el libro caiga en un pozo de silencio, y sin paradoja espero al mismo tiempo que el libro dure más que yo" (15-XII-1942).

Más importa, como decía, observar cómo se apropia y se integra en un paisaje de conjunto el mito de Ocnos que pretender un poco a la fuerza conectarlo con tal o cual aspecto específico del libro de dicho título. De todas formas podría ser sugerente intentar alguna lectura por esta dirección. Propongo la del poema dedicado a "José María Izquierdo". Este escritor sevillano es en cierto modo contrafigura de Cernuda (como exponente de una opción vital y literariamente opuesta) y encarnación para él del enigma de un hombre que, "por un error de amor" - amor a una ciudad-, desperdició su talento. Creo que lo importante no es lo más obvio, la tan cernudiana referencia desdeñosa, despreciativa, al "rincón provinciano, pendón de bandería regional" y a "los compadres que no podían comprenderle", sino precisamente la ejemplar tenacidad a pesar de todo de ese Ocnos-Izquierdo ("vencido, triste y oscuro" se le describe en el poema), su obstinada fidelidad a un ideal insensato pero admirable, su afán necesariamente infructuoso de resucitar el espíritu extinto de una ciudad "de espléndido pasado". No importa que para Cernuda sea indigno de ese esfuerzo el objeto o, lo que es lo mismo porque coinciden aquí, el destinatario del mismo; como en los casos del amor humano, lo que cuenta es el valor del acto en sí, un valor otorgado "haya o no correspondencia" por la disposición y entrega de quien lo vive. El comentario final del poema supone algo más que un homenaje "idealista" a Izquierdo:

Bécquer y Machado la dejaron tras sí. José María Izquierdo nunca la abandonó. Después de todo, iquién sabe! Durante sus horas de recogimiento silencioso, escuchando la música o en sus atardeceres junto al río, mientras se perdía así entre el ruido de los otros bajo el cielo nativo, tal vez gozó gloria mejor y más pura que ninguna ${ }^{24}$.

Dicho comentario encierra también la lección que aquella oscura figura tan distinta con su ejemplo transmite: una idea pura de la vida, y por tanto de la poesía, cuyo valor secreto no le viene de afuera; algo, en fin, que no puede medirse en términos de reconocimiento y utilidad.

24. Prosa Completa, 53. 
Dejo, para no alargar excesivamente estas páginas, el examen de otros poemas de Ocnos, para comentar por ejemplo la otra explicación (o racionalización) de Cernuda según la cual el asno sería "símbolo del tiempo que todo lo consume", y sobre todo del poema final, luego eliminado en las posteriores ediciones del libro, "Escrito en el agua". Todo ello parecería estar relacionado con el tema, suficientemente abordado por la crítica, de la expulsión de una Niñez-Paraíso gozosamente atemporal, y obedecería al propósito que presidió la redacción del primer Ocnos, la fijación y el rescate en sus páginas de una experiencia primigenia, fundamental en la configuración del ideal poético del autor.

Para terminar se diría que Ocnos en el libro de Cernuda emerge imprevistamente del Hades — donde habitualmente se le representa- y vive por un tiempo - fijo e imperecedero por la escritura - en contacto, más que en fusión, con el mundo natural. Si tuviera que escoger entre las figuraciones gráficas que la tradición nos ha legado del personaje la que mejor ilustrara la visión de Cernuda, creo que eligiría la pintura que se halla en el columbario romano de Villa Panfilia. Allí (traduzco la escueta nota de J. G. Frazer que la describe) "Indolencia aparece sentado ociosamente sobre una piedra y sostiene con su mano derecha el extremo de una soga, que está comiendo un asno, echado en el suelo, enfrente de él. Los edificios y los árboles del fondo prueban que la escena no tiene lugar en el mundo inferior". Ocio y trabajo se confunden en su labor y él, a la vez que forma parte del cuadro, es un distante contemplador del mismo. "La escena irradia paz", comenta Bachofen a propósito de esta pintura: "Parece como si el silencio del sepulcro se hubiese apoderado de la imagen" 25.

\section{Postdata}

La reciente consulta (gracias a Carlos-Peregrín Otero) del cuadernillo autógrafo de fechas conservado en Los Ángeles nos permite situar, aunque de forma todavía aproximada, el momento en que eligió Cernuda su título "Ocnos". Éste, en unas pocas entradas del cuadernillo hasta principios de 1941, parece que está interlineado (deduzco de ello que añadido algo después). La siguiente mención, en julio del mismo año, al corregir y pasar en limpio los poemas, ya muestra una clara constancia del título. Así pues, con toda probabilidad, la decisión tuvo lugar en el curso de la primera mitad de 1941, es decir, cuando el libro estaba ya sustancialmente escrito. 